\title{
Impact of Soil Erosion on Production in Cropping Systems. II.* Simulation of Production and Erosion Risks for a Wheat Cropping System
}

\author{
M. Littleboy, ${ }^{\mathrm{A}}$ D. M. Freebairn, ${ }^{\mathrm{B}}$ G. L. Hammer ${ }^{\mathrm{B}}$ and D. M. Silburn $^{\mathrm{B}}$ \\ A Land Management Research Branch, Queensland Department of \\ Primary Industries, Meiers Road, Indooroodilly, Qld 4068. \\ ${ }^{B}$ QDPI/CSIRI Agricultural Production Systems Research Unit, \\ P.O. Box 102, Toowoomba, Qld 4350.
}

\begin{abstract}
Maintenance of productive soil base by minimizing soil erosion is vital to long-term crop production. In this study, a modelling approach is used to estimate effects of soil erosion on productivity for a wheat cropping system at three locations in northeast Australia, Emerald, Dalby and Gunnedah. Predictions of erosion, runoff and yield decline due to erosion for variations in initial soil depth, slope and fallow management strategy are presented.

Rates of yield decline were highest at Emerald due to summer dominance of rainfall resulting in higher runoff during summer fallow periods. On average, soil depth decreased by $0.35 \mathrm{~cm}$ year $^{-1}$ at Emerald, $0.25 \mathrm{~cm}_{\text {year }}^{-1}$ at Dalby and $0.1 \mathrm{~cm}$ year $^{-1}$ at Gunnedah for a $5.0 \%$ slope, $100 \mathrm{~cm}$ initial soil depth and a disc/chisel fallow management strategy. Rates of soil removal and subsequent yield decline were higher for shallower soils, steeper slopes and if management practices provided less stubble cover during the fallow. The productivity half-life concept shows that the productive life of the soil was less than 100 years for some soil depth, climate, slope and management combinations. For other combinations, significant yield decline was predicted after 100 years of cropping.

The quantification of erosion-productivity relationships allows us to identify regions of higher risk, to estimate the utility of management options, and provide a basis for focusing research and development of management strategies to preserve long-term production.
\end{abstract}

Keywords: erosion, productivity, surface management, simulation.

\section{Introduction}

In the short-term, crop production depends on a number of factors including soil type, climate, management, and production hazards such as disease, insects, and climatic extremes. In the long-term, conservation of a productive soil base by minimizing soil erosion, is vital to maintain levels of crop production. Erosion of soil by water reduces productivity by decreasing soil depth and plant available water capacity, removing nutrients required for plant growth, and altering soil physical properties resulting in less water infiltration, poorer crop-establishment and root penetration.

Relationships between soil erosion and productivity are difficult to define. Historically, yield decline due to erosion has been masked by advances in technology such as use of fertilizer, higher yielding crop varieties, improved herbicides, insecticides and planting technology. In addition, it is often difficult

* Part I, Aust. J. Soil Res. 1992, 30, 757-74. 
to recognize that land is being eroded. This is due to both the sporadic nature of erosion (Freebairn and Wockner 1986) and, in some cases, low visual impact of erosion. Kimberlin and Moldenhauer (1977) stated that erosion rates less than $30 \mathrm{t} \mathrm{ha}^{-1}$ year $^{-1}$ are difficult to recognize and the National Soil ErosionProductivity Research Planning Committee (1981) suggested that erosion may not be noticed until the land is no longer viable for cropping.

Rate of productivity decline can be defined either through field experimentation or computer simulation modelling. Experimentation usually involves either scalping experiments, where different depths of topsoil are removed prior to planting, or comparison of eroded and uneroded paired sites. Differences in harvest yields are attributed to erosion.

In Australia, field experimentation has been the predominate technique for quantifying relationships between erosion and productivity. An early scalping experiment at Gunnedah in New South Wales was described by Barr (1957). Hamilton (1970) presented the results of scalping experiments at five locations in New South Wales over a period of 14 years, and P. J. White (unpublished data) conducted scalping experiments at three locations in southern Queensland. Each of these experiments showed a reduction in productivity with increased soil removal. However, it is unlikely that the artificial removal of soil is a true representation of the removal of soil by erosion, because of its unnatural modification of the physical and chemical properties of the soil (Bruce et al. 1987).

Models of various levels of complexity have been used to quantify relationships between erosion and productivity. Watt (1990) compiled results from a range of scalping experiments and derived a linear regression model to represent the relation between soil removal and productivity. The slope of this regression suggests that productivity decreases by $0.023 \%$ for every tonne of soil removal, regardless of soil properties. Hollingsworth et al. (1988) adapted the Productivity Index (PI) model of Pierce et al. (1983) for Australian conditions. The PI model relates productivity to inputs of annual erosion rate, plant available water capacity, maximum root depth, bulk density and pH. It assumes that erosion alters these properties which subsequently affect productivity. However, there is no effect of either climate variability or management in these models, and it assumed that the long-term average annual soil erosion is known. These limitations can be overcome by using a dynamic computer simulation model with long-term climate data.

Williams (1983) developed the Erosion-Productivity-Impact-Calculator (EPIC) model in the United States. This model contains daily water balance, soil erosion, and simple crop growth and grain yield models. EPIC is applicable for the range of soils, environments and crops encountered in the United States (Williamset al. 1983). However, EPIC has not been validated for Australian soils and climates, and uses crop models too simple to give good predictions of grain yield.

The computer simulation model, PERFECT, was developed and validated for cropping systems in the subtropical region of Queensland and northern New South Wales in Part I of this study (Littleboy et al. 1992). This model simulates the daily water balance, soil erosion, crop growth and yield in an agricultural system. It uses long-term climatic data, and model outputs are sensitive to parameters describing topography, soil properties, fallow management and cropping strategy. 
The objective of this study was to use PERFECT to quantify the effect of erosion on productivity, and determine how this effect is related to depth of soil, climate, topography and fallow management for Vertisols in selected grain growing areas of north-east Australia.

\section{Methods}

\section{Quantifying Effects of Erosion}

The cropping system simulation model, PERFECT, was described and validated in Part I (Littleboy et al. 1992). The impact of erosion on the soil profile was simulated by allowing soil depth, plant available water capacity and mineral nitrogen in the topsoil to decline as soil was eroded. Erosion was predicted on a daily basis using a Modified Universal Soil Loss Equation, MUSLE (Williams 1975), adapted for Vertisols in Queensland by Freebairn and Wockner (1986). A value of 0.4 was used for the MUSLE soil erodibility parameter, $K$ (Freebairn et al. 1989). Mineral nitrogen was removed from the topsoil by using the relationship from CREAMS (Knisel 1980):

$$
\text { SEDN }=\text { SOIL } \times \text { MNIT } \times \text { ENR, }
$$

where SEDN is the mineral nitrogen lost in sediment $\left(\mathrm{kg} \mathrm{ha}^{-1}\right)$; SOIL is the daily erosion $\left(\mathrm{kg} \mathrm{ha}^{-1}\right)$; MNIT is the mineral nitrogen in topsoil $\left(\mathrm{kg} \mathrm{kg}^{-1}\right)$; and ENR is the enrichment ratio.

The enrichment ratio predicts the preferential removal of nutrient-rich finer soil particles in eroded sediment and is usually related to the volume of sediment removed. However, Foster et al. (1985) found that enrichment of nutrients in sediment was high for sandy soil but negligible for clay soil. Therefore, for the Vertisol used in this study, it was assumed that enrichment was negligible and thus the enrichment ratio was assumed equal to 1 .

Yield reductions due to erosion were calculated by comparing simulations both with and without the effect of erosion. The first simulation assumed no effects of erosion on the soil profile but, in the second simulation, erosion reduced soil depth, plant available water capacity and mineral nitrogen in the topsoil. Differences in the predicted yield between the two simulations were attributed to erosion.

\section{Simulation Analysis}

PERFECT Version 1.0 (Littleboy et al. 1989) was used for all simulations in this study. All simulations were performed for wheat grown on a Vertisol at three locations: Emerald $\left(23^{\circ} 33^{\prime}\right.$ S., $148^{\circ} 10^{\prime}$ E. $)$, Dalby $\left(27^{\circ} 10^{\prime}\right.$ S., $151^{\circ} 17^{\prime}$ E. $)$ and Gunnedah $\left(30^{\circ} 56^{\prime}\right.$ S., $150^{\circ} 16^{\prime}$ E.). These sites lie roughly on a north-south transect from central Queensland to northern New South Wales and represent major grain production centres in Australia's north-east grain belt. Daily rainfall data for the period 1889-1988 were obtained from the Commonwealth Bureau of Meteorology for each location. Average weekly temperature and pan evaporation were obtained from the CSIRO AUSTCLIMWK Database. Average monthly rainfall, pan evaporation and temperature for the three sites are presented in Fig. 1.

Initially, a control simulation was performed for continuous wheat cropping at each location, assuming an initial soil depth of $100 \mathrm{~cm}$, plant available water capacity of $165 \mathrm{~mm}$, slope of $5 \%$ and a disc/chisel fallow management strategy. Each factor (depth, slope and management) was then varied individually from the control simulations. Three initial soil depths (50, 100 and $150 \mathrm{~cm})$, three slopes $(2 \cdot 5 \%, 5.0 \%$ and $7 \cdot 5 \%)$ and four fallow management strategies (stubble burnt, disc/chisel, stubble mulched and zero-tillage) were simulated. Initial moisture characteristics and mineral nitrogen for soil depths of 50,100 and $150 \mathrm{~cm}$ are given in Table 1. A slope length of $100 \mathrm{~m}$ was used for all simulations.

Percentage reductions in yield due to erosion were plotted against time for each 100 year simulation. A 5 year moving average was used to smooth out large variations caused by year to year climatic extremes.

\section{Results}

Climatic comparison of Emerald, Dalby and Gunnedah is presented in Fig. 1. Average annual rainfall is 647,688 and $602 \mathrm{~mm}$ for Emerald, Dalby and Gunnedah, 

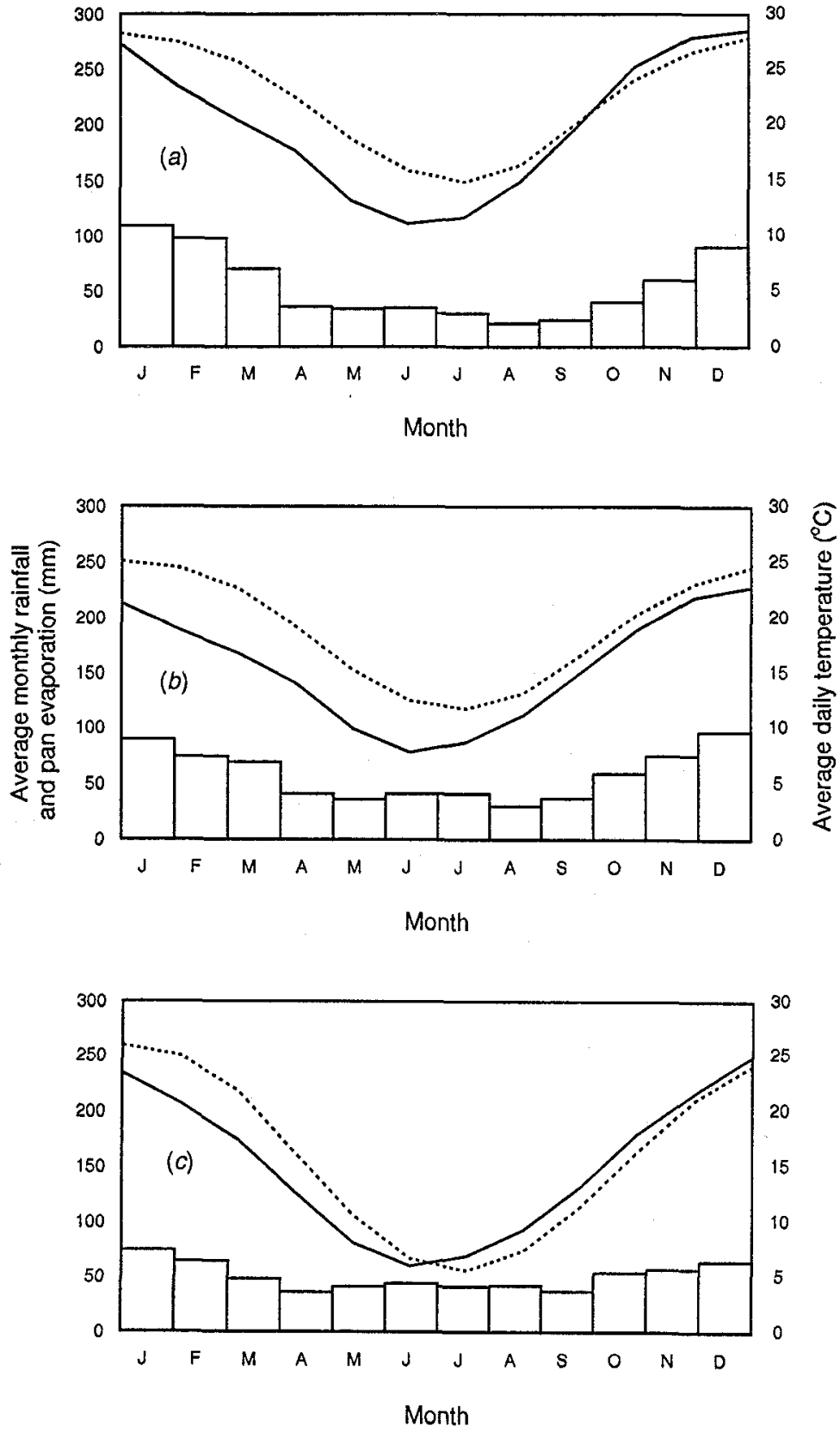

Fig. 1. Average monthly rainfall, average monthly pan evaporation and average daily temperature for (a) Emerald, (b) Dalby and (c) Gunnedah.

respectively. As latitude increases from Emerald to Gunnedah, rainfall becomes less summer dominant. At Emerald, average summer rainfall is $259 \mathrm{~mm}$ or $40 \%$ of the average annual rainfall, compared with $260 \mathrm{~mm} \mathrm{(38 \% )}$ at Dalby and $195 \mathrm{~mm}(32 \%)$ at Gunnedah. The opposite trend is evident for winter rainfall, with $99 \mathrm{~mm}(15 \%)$ at Emerald, $126 \mathrm{~mm}(18 \%)$ at Dalby, and $133 \mathrm{~mm}(22 \%)$ 
Table 1. Depth increments, volumetric soil moisture characteristics and mineral nitrogen for the Vertisol used in the simulation study

\begin{tabular}{rcccc}
\hline $\begin{array}{c}\text { Depth } \\
(\mathrm{cm})\end{array}$ & $\begin{array}{c}\text { Wilting } \\
\text { point } \\
(\%)\end{array}$ & $\begin{array}{c}\text { Field } \\
\text { capacity } \\
(\%)\end{array}$ & $\begin{array}{c}\text { Total } \\
\text { porosity } \\
(\%)\end{array}$ & $\begin{array}{c}\text { Available } \\
\text { nitrogen } \\
\left(\mathrm{g} \mathrm{m}^{-2}\right)\end{array}$ \\
\hline 10 & $15 \cdot 0$ & $35 \cdot 0$ & $40 \cdot 0$ & $5 \cdot 0$ \\
30 & $22 \cdot 5$ & $41 \cdot 0$ & $43 \cdot 75$ & $2 \cdot 5$ \\
50 & $22 \cdot 5$ & $39 \cdot 0$ & $41 \cdot 25$ & $0 \cdot 5$ \\
100 & $24 \cdot 0$ & $39 \cdot 0$ & $40 \cdot 0$ & $0 \cdot 5$ \\
150 & $25 \cdot 0$ & $36 \cdot 0$ & $38 \cdot 0$ & $0 \cdot 5$ \\
\hline
\end{tabular}

Table 2. Simulated average annual wheat yield and coefficient of variation (CV) at Emerald, Dalby and Gunnedah A soil depth of $100 \mathrm{~cm}$, a $5 \cdot 0 \%$ slope and a disc/chisel fallow were simulated

\begin{tabular}{lcc}
\hline Location & Mean $\left(\mathrm{t} \mathrm{ha}^{-1}\right)$ & CV (\%) \\
\hline Emerald & 1.74 & 32 \\
Dalby & 1.78 & 31 \\
Gunnedah & 2.06 & 41 \\
\hline
\end{tabular}

Table 3. Simulated average annual soil erosion $\left(\mathrm{t} \mathrm{ha}^{-1}\right)$ for three slopes, three soil depths and four fallow management strategies, stubble burnt (B), disc/chisel (D), stubble mulched (M) and zero-tillage $(Z)$ at Emerald, Dalby and Gunnedah

\begin{tabular}{lrccccccccc}
\hline Location & \multicolumn{3}{c}{ Slope (\%) } & \multicolumn{4}{c}{ Soil depth (cm) } & \multicolumn{4}{c}{ Management } \\
& $2 \cdot 5$ & $5 \cdot 0$ & $7 \cdot 5$ & 50 & 100 & 150 & B & D & M & Z \\
\hline Emerald & 13 & 33 & 62 & 46 & 33 & 32 & 70 & 33 & 10 & 3 \\
Dalby & 9 & 23 & 42 & 39 & 23 & 21 & 51 & 23 & 8 & 3 \\
Gunnedah & 4 & 10 & 18 & 17 & 10 & 9 & 29 & 10 & 3 & 1 \\
\hline
\end{tabular}

at Gunnedah. As latitude increases from Emerald to Gunnedah, the difference between evaporation and rainfall diminishes resulting in a higher evaporation deficit at Emerald, especially during winter. Temperature decreases as latitude increases.

The production potential of the three sites is summarized in Table 2. Average wheat yield for a 100 year simulation was lowest at Emerald and highest at Gunnedah. For a $100 \mathrm{~cm}$ soil depth, average wheat yield was $1.7 \mathrm{t} \mathrm{ha}^{-1}$ at Emerald, $1.8 \mathrm{t} \mathrm{ha}^{-1}$ at Dalby and $2.1 \mathrm{t} \mathrm{ha}^{-1}$ at Gunnedah. Variability of wheat yield was similar for Emerald and Dalby, with coefficients of variation of $32 \%$ and $31 \%$, respectively. However, at Gunnedah, wheat yield was more variable (coefficient of variation of $41 \%$ ).

Predicted annual soil erosion for the climate, soil depth, slope and fallow management options considered in this study is given in Table 3. Average annual erosion increased with lower latitudes. On average, $50 \%$ more erosion occurred at Emerald than at Dalby, and $100 \%$ more erosion occurred at Dalby than at Gunnedah. An increase in slope from $2 \cdot 5 \%$ to $7.5 \%$ increased erosion by up to 4 fold, 

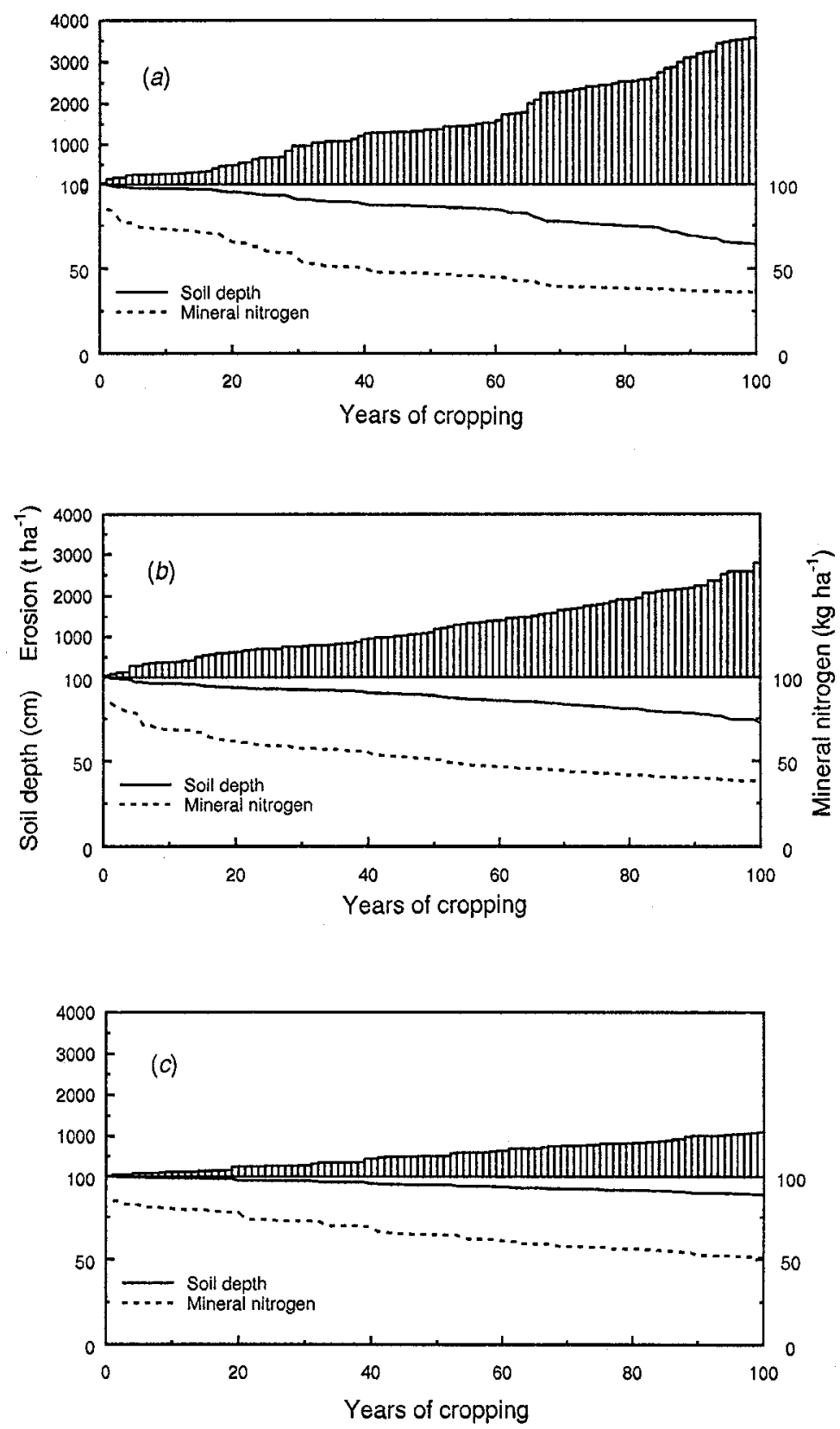

Fig. 2. Simulated soil depth, mineral nitrogen in topsoil, and cumulative soil erosion for $(a)$ Emerald, (b) Dalby and (c) Gunnedah. An initial soil depth of $100 \mathrm{~cm}$, a slope of $5 \cdot 0 \%$ and disc/chisel fallow management practice were simulated.

regardless of location. At all locations, a change in the fallow management strategy from zero-tillage to stubble burnt results in a 20 -fold increase in predicted erosion. In contrast, soil depth has a smaller effect on erosion. A decrease in soil depth from 150 to $50 \mathrm{~cm}$ caused erosion to double. 
The dynamic effects of erosion on the soil during the 100 year simulation under control conditions (continuous wheat cropping, $100 \mathrm{~cm}$ initial soil depth, $5 \cdot 0 \%$ slope and a disc/chisel fallow management) are shown in Fig. 2. At each site, soil depth and mineral nitrogen in the topsoil decreased as cumulative erosion increased. On average, soil depth decreased by $0.35 \mathrm{~cm}_{\text {year }}{ }^{-1}$ at Emerald, $0.25 \mathrm{~cm}_{\text {year }}{ }^{-1}$ at Dalby and $0.1 \mathrm{~cm}_{\text {year }}{ }^{-1}$ at Gunnedah. Greater than $50 \mathrm{~kg} \mathrm{ha}^{-1}$ of mineral nitrogen was removed at all sites during the 100 year simulation.

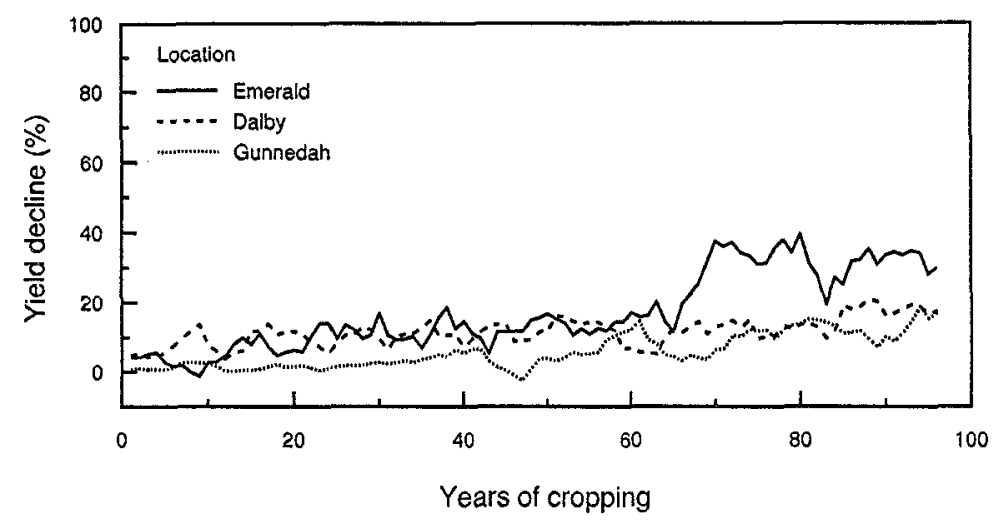

Fig. 3. Simulated percentage decline in wheat yield for three locations in north-east Australia. A initial soil depth of $100 \mathrm{~cm}$, a slope of $5.0 \%$ and a disc/chisel fallow management practice were simulated.

The dynamic effects of erosion on wheat yield decline during the 100 year simulation under control conditions (continuous wheat cropping, $100 \mathrm{~cm}$ initial soil depth, $5.0 \%$ slope and a disc/chisel fallow management) are shown in Fig. 3. Decline in wheat yield due to erosion was highest at Emerald where productivity had decreased by $40 \%$ after 100 years of cropping. At both Dalby and Gunnedah, decline in wheat yield was $20 \%$ after 100 years of cropping.

Table 4. Simulated average annual runoff $(\mathrm{mm})$ for three slopes, three soil depths and four fallow management strategies, stubble burnt (B), disc/chisel (D), stubble mulched (M) and zero-tillage (Z) at Emerald, Dalby and Gunnedah

\begin{tabular}{lcccccccccc}
\hline Location & \multicolumn{3}{c}{ Slope (\%) } & \multicolumn{3}{c}{ Soil depth (cm) } & \multicolumn{3}{c}{ Management } \\
& $2 \cdot 5$ & $5 \cdot 0$ & $7 \cdot 5$ & 50 & 100 & 150 & B & D & M & Z \\
\hline Emerald & 99 & 99 & 99 & 118 & 99 & 95 & 116 & 99 & 90 & 91 \\
Dalby & 66 & 66 & 66 & 87 & 66 & 61 & 83 & 66 & 59 & 59 \\
Gunnedah & 38 & 38 & 38 & 51 & 38 & 33 & 49 & 38 & 33 & 35 \\
\hline
\end{tabular}

A summary of predicted annual runoff for the climate, soil depth, slope and fallow management options considered in this study is given in Table 4. Average annual runoff increased with lower latitudes, with $50 \%$ more runoff occurring at Emerald than at Dalby, and $75 \%$ more runoff occurring at Dalby than at Gunnedah. A decrease in initial soil depth from 150 to $50 \mathrm{~cm}$ increased runoff by $25-50 \%$. Similar variations of $25-50 \%$ were predicted for the effect of fallow management on runoff. 

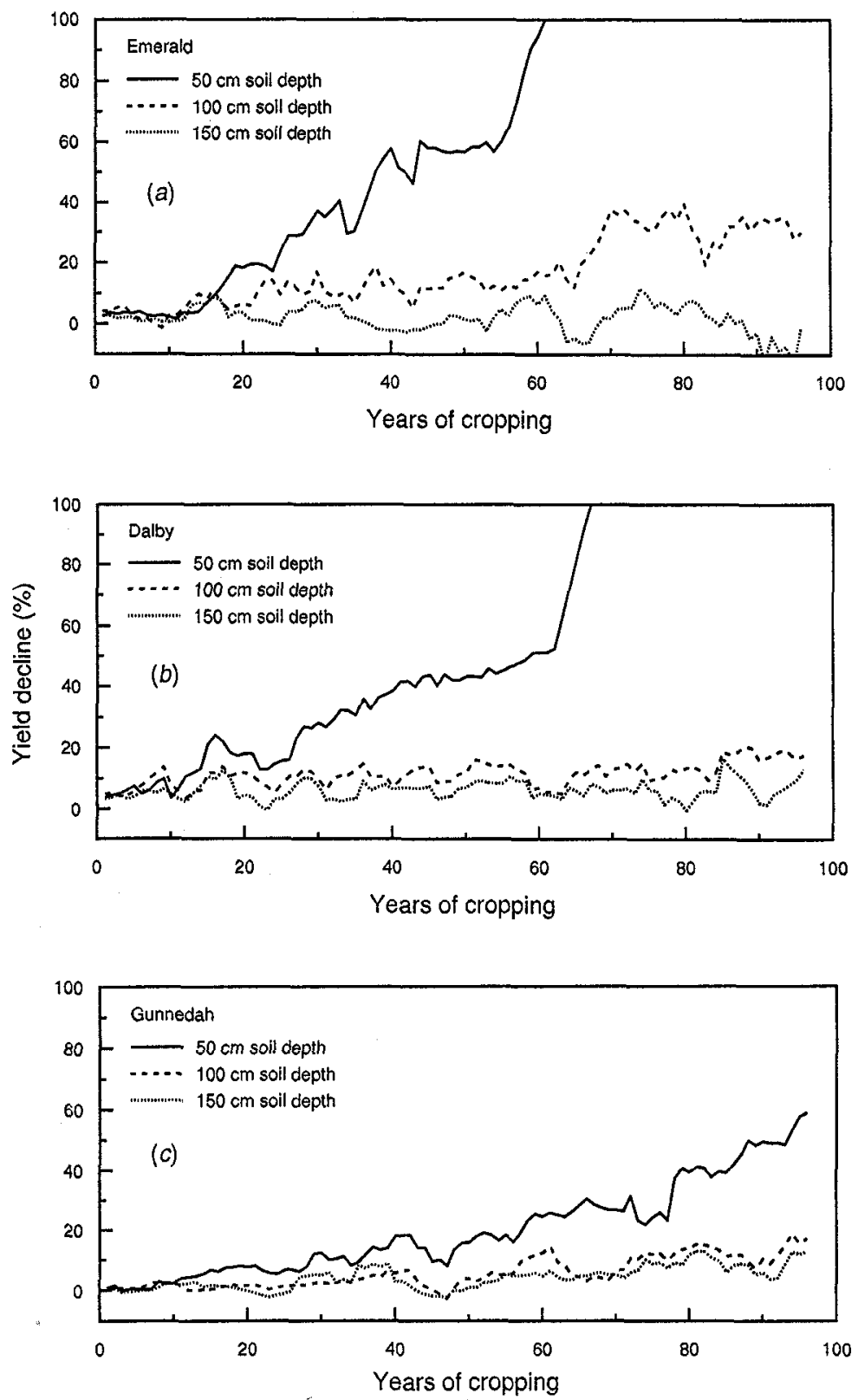

Fig. 4. Simulated percentage decline in wheat yield versus years of cropping for soil with initial depth of 50, 100, or $150 \mathrm{~cm}$ for $(a)$ Emerald, (b) Dalby and (c) Gunnedah. A slope of $5.0 \%$ and a disc/chisel fallow management practice were simulated.

\section{Effect of Soil Depth}

In comparison with the control simulation (100 cm initial soil depth), decline in wheat yield due to soil erosion was greater on the $50 \mathrm{~cm}$ initial soil depth and less on the $150 \mathrm{~cm}$ initial soil depth at all three locations (Fig. 4). At both 
Emerald and Dalby, the shallow $50 \mathrm{~cm}$ initial soil depth was totally depleted after approximately 60 years of cropping, while yield decline of $60 \%$ after 100 years of cropping was estimated on the shallow $(50 \mathrm{~cm})$ initial soil depth at Gunnedah. At all three locations, there was little impact of erosion on yield after 100 years of simulation on the $150 \mathrm{~cm}$ initial soil depth.
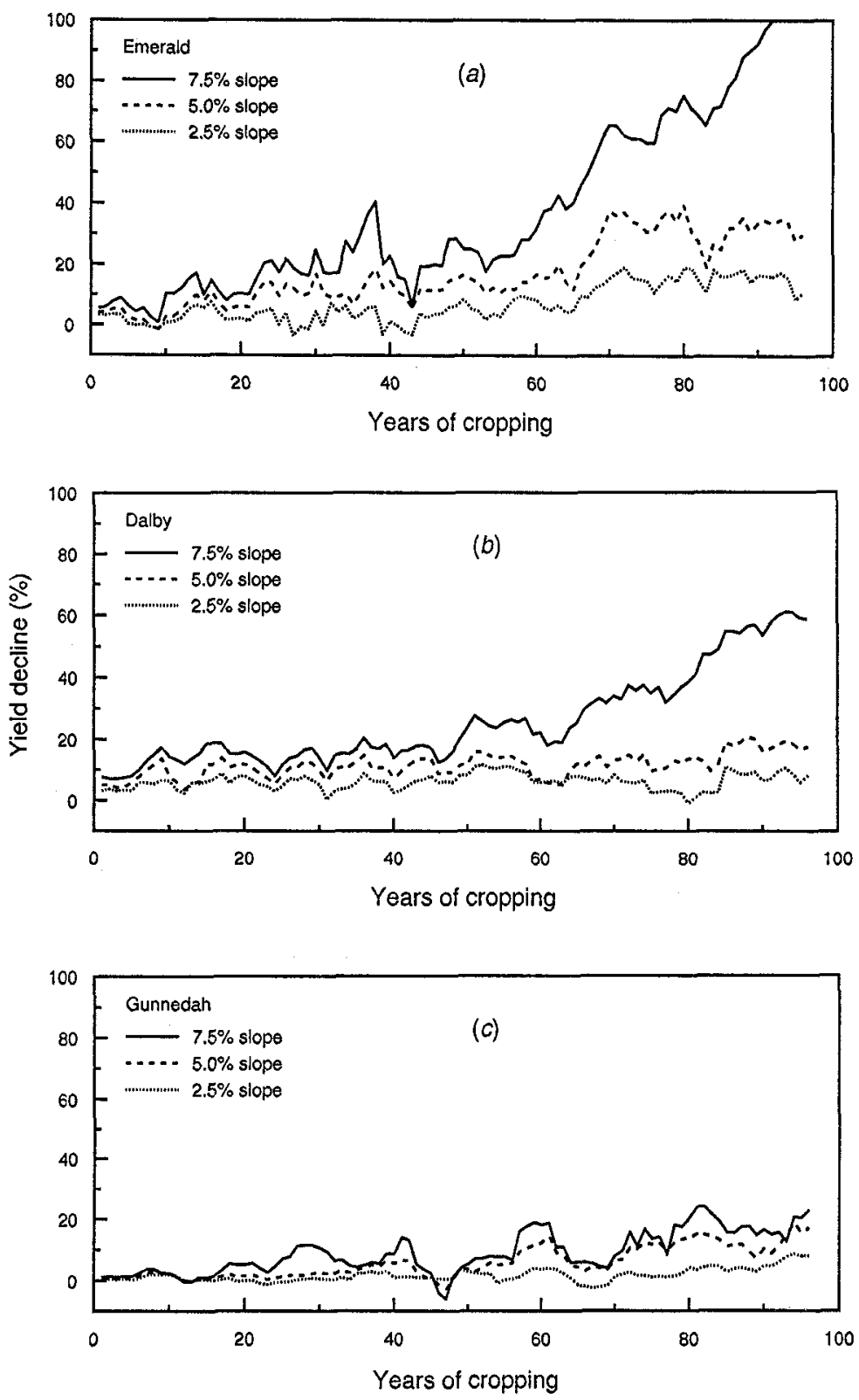

Fig. 5. Simulated percentage decline in wheat yield versus years of cropping with slope of $2.5 \%, 5.0 \%$ or $7.5 \%$ at (a) Emerald, (b) Dalby and (c) Gunnedah. An initial soil depth of $100 \mathrm{~cm}$ and a disc/chisel fallow management practice were simulated. 


\section{Effect of Slope}

In comparison with the control simulation ( $5.0 \%$ slope), decline in wheat yield due to soil erosion was greater with the $7.5 \%$ slope and less with the $2 \cdot 5 \%$ slope at all three locations (Fig. 5). The largest effect of slope was evident at Emerald, where the soil was totally depleted after 90 years of cropping on a $7 \cdot 5 \%$ slope. Yield declines after 100 years of cropping for the other slope categories at Emerald were $15 \%$ for the $2.5 \%$ slope, and $30 \%$ for the $5.0 \%$ slope. In contrast, at Dalby and Gunnedah, increasing slope from $2.5 \%$ to $7.5 \%$ changed the yield decline after 100 years of cropping from $5 \%$ to $60 \%$ and $5 \%$ to $20 \%$, respectively.

\section{Effect of Fallow Management}

In comparison with the control simulation (disc/chisel), decline in wheat yield due to erosion associated with fallow management stretegy was greater with stubble burnt and less with either stubble mulched or zero-tillage at all three locations (Fig. 6). At Emerald, stubble burning resulted in an $80 \%$ yield decline after 100 years compared with $10 \%$ for zero-tillage. At Dalby and Gunnedah, the trends were identical, but the magnitudes were less. After 100 years at Dalby, declines in yield were $50 \%$ for stubble burnt management and only $5 \%$ for zero-tillage. The corresponding declines in yield due to erosion at Gunnedah were $30 \%$ and $5 \%$.

\section{Discussion}

\section{Factors Affecting Erosion Rates}

This study has quantified the effect of soil erosion on productivity for a wheat-cropping system on a Vertisol in north-east Australia by examining the degree of yield decline with time. We have shown that soil depth, slope, fallow management and climate affect amount of soil eroded and long-term productivity. For some combinations, the productive life of the soil ended within 100 years of cropping. For other combinations, substantial yield decline was predicted after 100 years of cropping.

Large variations in average annual erosion were predicted for the slope, soil depth and management options considered. In contrast, variations in average annual runoff were small compared with erosion. There was a $2000 \%$ (20-fold) variation in the amount of soil erosion for the range of fallow management strategies, compared with a variation of only $25-50 \%$ for runoff. A change in slope from $2.5 \%$ to $7.5 \%$ resulted in a $400 \%$ (4-fold) increase in the amount of soil erosion but no effect on runoff, as PERFECT does not include an algorithm relating slope to runoff. A reduction in soil depth from 150 to $50 \mathrm{~cm}$ doubled the amount of erosion, whereas runoff was increased by only $25-50 \%$. Therefore, the effects of slope, soil depth and management on erosion dominated any effects caused by differences in predicted runoff.

The dominant trend in all simulations was the decrease in both degradation and yield decline as latitude increased. This trend reflects the change from the more uniform monthly rainfall distribution at Gunnedah to the summer dominant rainfall pattern at Emerald (Fig. 1). For the summer-dominant rainfall pattern, large amounts of rainfall occurred during the summer fallow period, producing higher runoff volumes and erosion losses. However, a smaller proportion of rainfall 

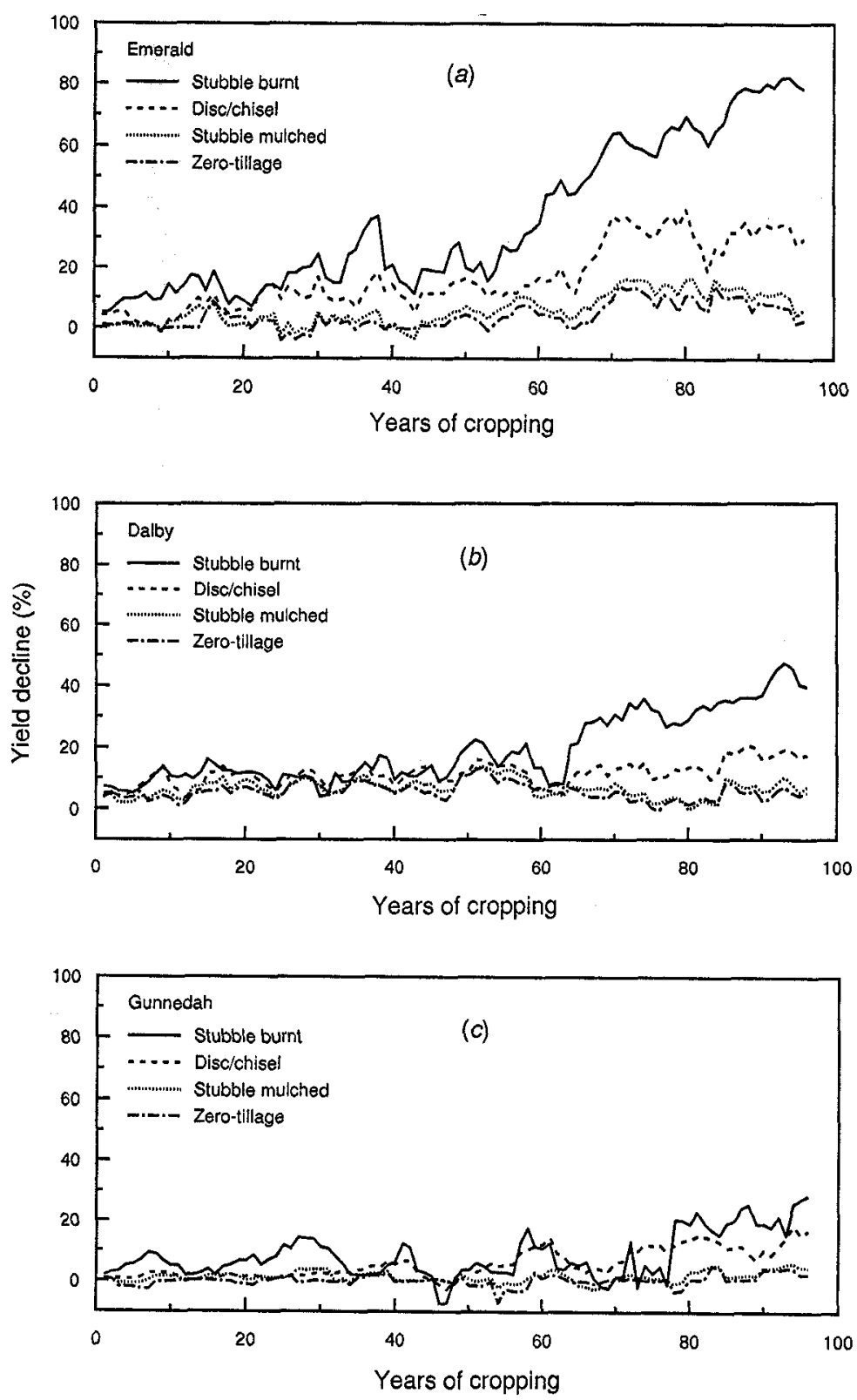

Fig. 6. Simulated percentage decline in wheat yield versus years of cropping associated with a fallow management strategy of stubble burnt, disc/chisel, stubble mulched or zero-tillage at (a) Emerald, (b) Dalby and (c) Gunnedah. An initial soil depth of $100 \mathrm{~cm}$ and a $5.0 \%$ slope were simulated.

at Gunnedah is received during the summer months resulting in less runoff and erosion during the fallow. At Gunnedah, the increase in winter rainfall also caused predicted yields to increase, producing higher levels of stubble cover during the fallow. The combination of these two factors decreased the rate of degradation as latitude increased. 
When studied individually, variations to soil depth, slope and fallow management had a substantial impact on erosion and productivity, regardless of climate. A combination of a number of factors, for example, steep slope, shallow soil, and less conservative fallow management would invariably produce higher erosion rates and quicker yield declines than presented here. In contrast, deep soils on low slopes where stubble retention practices are used would experience minimal productivity decline.

\section{Productivity Half-life}

An index of the impact of soil erosion on productivity is the concept of a productivity half-life of the soil $\left(P_{1 / 2}\right)$. That is, the time taken for a soil to lose $50 \%$ of its production potential. The $P_{1 / 2}$ of the shallow $50 \mathrm{~cm}$ initial soil depth was 38,58 and 87 years at Emerald, Dalby and Gunnedah, respectively. The $P_{1 / 2}$ of the deep soils at all locations was greater than 100 years. At all locations, rate of yield decline was highest for shallow soils which implies that higher plant available water capacities act as a buffer against erosion.

An increase in slope results in higher rates of erosion and yield decline, with the largest decline predicted at Emerald due to the summer dominant rainfall distribution. The $P_{1 / 2}$ for the highest slope considered $(7 \cdot 5 \%)$ was 68,80 and greater than 100 years at Emerald, Dalby and Gunnedah respectively. At all locations, the $P_{1 / 2}$ of the shallowest slope $(2 \cdot 5 \%)$ was greater than 100 years.

Stubble retention in zero-tillage and stubble mulched management practices increases stubble cover during the fallow. Management strategies incorporating these practices resulted in less erosion and lower rates of yield decline. On the other hand, low cover levels, if stubble is burnt after harvest, were shown to greatly increase erosion and decrease productivity. The $P_{1 / 2}$ for the stubble burnt treatment was 65, 100 and $>100$ years for Emerald, Dalby and Gunnedah respectively. In contrast, $P_{1 / 2}$ for the zero-tillage treatment was greater than 100 years. The summer-dominant rainfall distribution at Emerald caused higher rates of yield decline at that site. An increase in cover may result from the use of cropping systems other than wheat monoculture. Examination of alternative cropping systems is the subject of further research.

\section{Dynamics of Erosion-Productivity}

In some years, yields were slightly higher for the degraded soil than the undegraded soil as indicated by negative values in Figs 4-6. This trend was only evident in years when low yields were predicted and was a result of the dynamic nature of the leaf area growth and transpiration components of the wheat model. Lower levels of mineral nitrogen and plant available water capacity in the degraded soil resulted in less leaf area growth and transpiration compared with the undegraded soil. At the critical developmental stage of flowering, the crop on the undegraded soil had exhausted the soil water store while the crop on the degraded soil still had water available for crop uptake. Hence, lower yields vere predicted for the undegraded soil because the wheat model relates grain yield to water use around flowering (Woodruff and Tonks 1983).

Under conditions where substantial yield decline was predicted, it was evident that the rate of decline tended to become greater as years of cropping increased. 


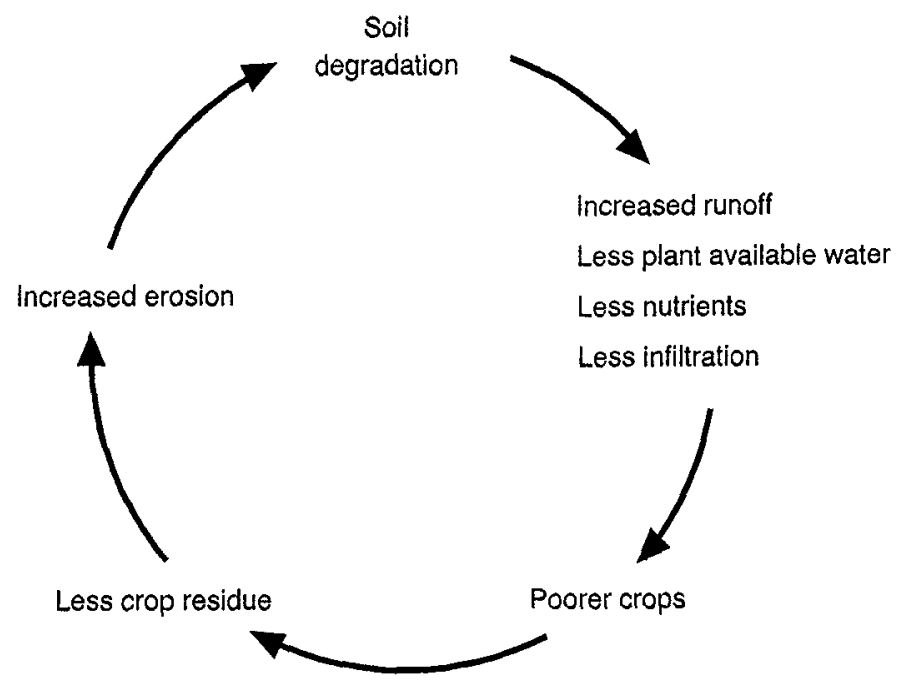

Fig. 7. Idealized representation of the erosion-productivity cycle in cropping lands.

Fig. 7 shows an idealized representation of the erosion-productivity cycle. Soil degradation caused by erosion reduces plant available water capacity and available nutrients and this in turn reduces biomass production. Consequently, less crop residue cover during the following fallow results in more soil erosion and degradation. Degradation of the soil profile and subsequent yield decline will increase rapidly as this cycle evolves. The gradual increase in slope of the cumulative soil loss in Fig. 2 supports this proposition. The sudden declines in wheat yield for Emerald and Dalby in Fig. 4 are the result of this cycle.

\section{Conclusions}

The simulations presented are conservative estimates of the impact of erosion on productivity. The version of PERFECT used here assumes that erosion affects only soil depth, plant available water capacity and mineral nitrogen in the topsoil. Incorporation of algorithms including other nutrients and modification of soil physical properties affecting infiltration characteristics, crop establishment, and root penetration will provide more confidence in model predictions. On the other hand, no attempt has been made to incorporate effects of technology, such as improved genotypes or fertilizer management.

This study has shown the power of current computer simulation models to provide predictions of long-term productivity. A modelling approach is the only practical way to quantify risks associated with long-term production from agricultural systems. Whilst no model is perfect, a cropping systems model such as PERFECT, can be used to simulate numerous combinations of climate, soil type, topography, fallow management and cropping system. Quantifying erosion-productivity relationships provides a basis of determining the cost of soil erosion to the community. Such an analysis identifies regions of higher risk, demonstrates the utility of management options, and provides a basis for focusing both research and development of management strategies to preserve levels of production. 


\section{Acknowledgments}

The Land and Water Resources Research and Development Corporation (formerly National Soil Conservation Program) provided partial funding of the work described in this paper.

\section{References}

Barr, D. A. (1957). The effect of sheet erosion on wheat yield. Journal of the Soil Conservation Service of New South Wales 13, 27-32.

Bruce, R. R., Wilkinson, S. R., and Langdale, G. W. (1987). Legume effects on soil erosion and productivity. In 'The Role of Legumes in Conservation Tillage Systems'. (Ed. J. F. Power.) pp. 127-38. (Soil Conservation Society of America.)

Foster, G. R., Young, R. A., and Neibling, W. H. (1985). Sediment composition for nonpoint source pollution analysis. Transactions, American Society of Agricultural Engineers 29, 133-9.

Freebairn, D. M., Silburn, D. M., and Loch, R. J. (1989). Evaluation of three soil erosion models for clay soils. Australian Journal of Soil Research 27, 199-211.

Freebairn, D. M., and Wockner, G. H. (1986). A study of soil erosion on Vertisols of the Eastern Darling Downs, Queensland. II. The effect of soil, rainfall, and flow conditions on suspended sediment' losses. Australian Journal of Soil Research 24, 159-72.

Hamilton, G. J. (1970). The effect of sheet erosion on wheat yield and quality. Journal of the Soil Conservation Service of New South Wales 26, 118-23.

Hollingsworth, I., Wells, T., and Perrens, S. (1988). 'PI-A Soil Degradation Model.' (Department of Resource Engineering, University of New England: Armidale.)

Kimberlin, L. W., and Moldenhauer, W. C. (1977). Proceedings National Symposium on Soil Erosion and Sedimentation by Water. American Society of Agricultural Engineers Publication No. 4-77, pp. 31-42.

Knisel, W. G. (1980). 'CREAMS: A Field-Scale Model for Chemicals, Runoff, and Erosion from Agricultural Management Systems.' United States Department of Agriculture Conservation Research Report Number 26.

Littleboy, M., Silburn, D. M., Freebairn, D. M., Woodruff, D. R., and Hammer, G. L. (1989). PERFECT, A computer simulation model of Productivity, Erosion, Runoff Functions to Evaluate Conservation Techniques. Queensland Department of Primary Industries Bulletin QB89005.

Littleboy, M., Silburn, D. M., Freebairn, D. M., Woodruff, D. R., and Hammer, G. L. (1992). Impact of soil erosion on production in cropping systems. I. Development and validation of a computer simulation model. Australian Journal of Soil Research 30, 757-74.

National Soil Erosion-Soil Productivity Research Planning Committee (1981). Soil erosion effects on soil productivity: A research perspective. Journal of Soil and Water Conservation 36, 82-90.

Pierce, F. J., Larson, W. E., Dowdy, R. H., and Graham, W. A. P. (1983). Productivity of soils: Assessing long-term changes due to erosion. Journal of Soil and Water Conservation 38, 39-44.

Watt, L. A. (1990). Effect of soil erosion on productivity-A review of experimental results. Australian Journal of Soil and Water Conservation 3, 50-2.

Williams, J. R. (1975). Sediment-yield prediction with universal equation using runoff energy factor. In 'Present and Prospective Technology for Predicting Sediment Yields and Sources'. pp. 244-52. United States Department of Agriculture, ARS-S-40.

Williams, J. R. (1983). 'EPIC, The Erosion-Productivity Impact Calculator, Volume 1. Model Documentation.' Agricultural Research Service, United States Department of Agriculture.

Williams, J. R, Renard, K. G., and Dyke, P. T. (1983). EPIC. A new method for assessing erosion's effect on soil productivity. Journal of Soil and Water Conservation 38, 381-3.

Woodruff, D. R., and Tonks, J. (1983). Relationship between time of anthesis and grain yield of wheat genotypes with differing developmental patterns. Australian Journal of Agricultural Research 34, 1-11. 